\title{
Special issue for the 13th world congress on structural and multidisciplinary optimization-editorial note
}

\author{
Erdem Acar ${ }^{1} \cdot$ Jianbin $\mathrm{Du}^{2} \cdot$ Yoon Young $\mathrm{Kim}^{3} \cdot$ Mehmet Polat Saka $^{4} \cdot$ Ole Sigmund ${ }^{5} \cdot$ Emilio Carlos Nelli Silva $^{6}$
}

Received: 11 March 2020 / Revised: 11 March 2020 / Accepted: 12 March 2020 / Published online: 23 March 2020

(C) Springer-Verlag GmbH Germany, part of Springer Nature 2020

The purpose of this special issue of the Journal of Structural and Multidisciplinary Optimization is to publish selected works presented at the 13th World Congress on Structural and Multidisciplinary Optimization (WCSMO13) in May 20-24, 2019, in Beijing, China. WCSMO conferences, held biennially in different continents, aim to provide a platform for researchers and practitioners from all over the world to present and discuss the latest findings and developments in all areas of structural and multidisciplinary optimization. WCSMO13 was organized jointly by the Chinese Society of Theoretical and Applied Mechanics, Dalian University of Technology, and Beihang University under the auspices of the Asian Society of Structural and Multidisciplinary Optimization (ASSMO) and the International Society for Structural and Multidisciplinary Optimization (ISSMO).

Based on nominations by WCSMO participants and own screenings, the guest editors selected the special issue papers through a selection process based on quality of the work and diversity of the topics concerning the analysis of solids, fluids,

Responsible Editor: Raphael Haftka

Erdem Acar

acar@etu.edu.tr; erdem.acar@gmail.com

1 Department of Mechanical Engineering, TOBB University of Economics and Technology, Söğ̈ütözü, 06560 Ankara, Turkey

2 School of Aerospace Engineering, Tsinghua University, Beijing 100084, China

3 Department of Mechanical Engineering, Seoul National University, Seoul 08826, South Korea

4 Civil Engineering Department, University of Bahrain, Zallaq, Bahrain

5 Department of Mechanical Engineering, Technical University of Denmark, 2800 Lyngby, Denmark

6 Department of Mechatronics and Mechanical Systems Engineering, University of São Paulo, São Paulo, SP 05508-030, Brazil manufacturing, and other fields. Subsequently, all manuscripts went through a regular review process. The issue includes a wide variety of contributions, ranging from theoretical developments to industrial applications, with topics related to topology optimization, surrogate based optimization, design optimization under uncertainty, and others.

The contributions in this issue can be listed as follows:

1. Data-driven design approach to hierarchical hybrid structures with multiple lattice configurations (https:// doi.org/10.1007/s00158-020-02497-4), Z. Liu, L. Xia, Q. Xia, and T. Shi.

2. Variational sensitivity analysis of elastoplastic structures applied to optimal shape of specimens (https://doi.org/ 10.1007/s00158-020-02492-9), J. Liedmann and F-J. Barthold.

3. Topology optimization of connections in mechanical systems (https://doi.org/10.1007/s00158-020-02511-9), L. Rakotondrainibe, G. Allaire, and P. Orval.

4. Topology optimization for periodic multi-component structures with stiffness and frequency criteria (https:// doi.org/10.1007/s00158-019-02481-7), S. Thomas, Q. $\mathrm{Li}$, and G. Steven.

5. Topology optimization of support structure layout in metal-based additive manufacturing accounting for thermal deformations (https://doi.org/10.1007/s00158-02002512-8), J. Pellens, G. Lombaert, M. Michiels, T. Craeghs, and M. Schevenels.

6. Uncertainty quantification and statistical model validation for an offshore jacket structure panel given limited test data and simulation model (https://doi.org/10.1007/ s00158-020-02520-8), M-Y. Moon, H-S. Kim, K. Lee, B. Park, and K.K. Choi.

7. Multigrid reduced-order topology optimization (https:// doi.org/10.1007/s00158-020-02570-y), M. Xiao, D. Lu, P. Breitkopf, B. Raghavan, W. Zhang, and S. Dutta.

8. Modeling and optimization with Gaussian processes in reduced eigenbases (https://doi.org/10.1007/s00158- 
019-02458-6), D. Gaudrie, R.L. Riche, V. Picheny, B. Enaux, and V. Herbert.

9. A multi-fidelity surrogate model based on support vector regression (https://doi.org/10.1007/s00158-020-02522-6), M. Shi, L. Lv, W. Sun, and X. Song.

10. Support optimization in additive manufacturing for geometric and thermo-mechanical constraints (https://doi. org/10.1007/s00158-020-02551-1), G. Allaire, M. Bihr, and B. Bogosel.

11. Reliability-based multi-scale design optimization of composite frames considering structural compliance and manufacturing constraints (https://doi.org/10.1007/ s00158-020-02517-3), Z. Duan, Y. Jung, J. Yan, and I. Lee.

12. Topology optimization of easy-removal support structures for additive manufacturing (https://doi.org/10. 1007/s00158-020-02607-2), M. Zhou, Y. Liu, and C. Wei.

13. Space-time topology optimization for additive manufacturing: concurrent optimization of structural layout and fabrication sequence (https://doi.org/10. 1007/s00158-019-02420-6), W. Wang, D. Munro, C. C.L. Wang, F. van Keulen, and J. Wu. ${ }^{1}$

14. Additive Manufacturing Scanning Paths Optimization Using Shape Optimization Tools (https://doi.org/10. 1007/s00158-020-02614-3), M. Boissier, G. Allaire, and $\mathrm{C}$. Tournier.

15. Misalignment topology optimization with manufacturing constraints (https://doi.org/10.1007/s00158-02002496-5), S. Bauduin, P. Alarcon, E. Fernandez, and P. Duysinx.

16. A framework for topology optimization of inertial microfluidic particle manipulators (https://doi.org/10. 1007/s00158-019-02483-5), C.S. Andreasen.

17. Topology optimization for designing periodic microstructures based on finite strain viscoplasticity (https:// doi.org/10.1007/s00158-020-02555-x), N. Ivarsson, M. Wallin, and D.A. Tortorelli.

18. Fiber bundle topology optimization of hierarchical microtextures for wetting behavior in Cassie-Baxter mode (https://doi.org/10.1007/s00158-020-02558-8), Y. Deng, W. Zhang, Z. Liu, J. Zhu, and J.G. Korvink.

19. Efficient limitation of resonant peaks by topology optimization including modal truncation augmentation (https://doi.org/10.1007/s00158-019-02471-9), A. Delissen, F. van Keulen, and M. Langelaar.

20. Eigenfrequency constrained topology optimization of finite strain hyperelastic structures (https://doi.org/10. 1007/s00158-020-02557-9), A. Dalklint, M. Wallin, and D.A. Tortorelli.

21. A new stochastic gradient method for the efficient solution of structural optimization problems with infinitely many states (https://doi.org/10.1007/s00158-02002571-x), L. Pflug, N. Bernhardt, M. Grieshammer, and M. Stingl.

22. Data-driven metamaterial design with Laplace-Beltrami spectrum as 'Shape-DNA' (https://doi.org/10.1007/ s00158-020-02523-5), L. Wang, Y-C. Chan, Z. Liu, P. Zhu, and W. Chen.

23. Numerical investigation of stiffness and buckling response of simple and optimized infill structures (https://doi.org/10.1007/s00158-020-02525-3), F. Wang and O. Sigmund.

Acknowledgments We are thankful to the Structural and Multidisciplinary Optimization community for nominating diverse high quality contributions to be included in this special issue. We are grateful to all the reviewers for volunteering their time, and for their timely and constructive comments. The guest editors would also like to thank SMO Editors Helder C. Rodrigues and Raphael T. Haftka for organizing and supporting this special issue. It goes without saying that even with all the editorial and review effort this special issue could not happen without the extraordinary effort of the conference organizers or the remarkable contributions by the authors.

\section{Compliance with ethical standards}

Conflict of interest The authors declare no conflict of interest.

Publisher's note Springer Nature remains neutral with regard to jurisdictional claims in published maps and institutional affiliations.

\footnotetext{
${ }^{1}$ Structural and Multidisciplinary Optimization (2020) 61:1-18. https://doi. org/10.1007/s00158-019-02420-6
} 